\title{
Fighter, Corpsman, Partisan an Attempt to Typify Former Soldiers Based on their Coping and Defense Mechanisms
}

\author{
Loni Brants ${ }^{1}$ (D) Katrin Schuy ${ }^{1} \cdot$ Simone Dors $^{1} \cdot$ Marie Horzetzky $^{1}$. \\ Heinrich Rau $^{2} \cdot$ Gerd Willmund $^{2} \cdot$ Andreas Ströhle $^{1} \cdot$ Stefan Siegel $^{1}$
}

Published online: 2 December 2019

(C) The Author(s) 2019

\begin{abstract}
This work strives to develop a typological classification of the use of conscious and unconscious defense and coping mechanisms based on methodically and structurally collected data from a qualitative survey of 43 former soldiers in Germany. Seven coping and defense types were identified: the Fighter, the Comrade, the Corpsman, the Strategist, the Partisan, the Self-Protector and the Infantryman. The types identified differed with regard to the accumulation, combination, and use of their conscious and unconscious defense and coping mechanisms in the superordinate areas of behaviour, relationships, emotions, reflexivity and time focus. The typological classification could offer psychotherapeutic interventions tailored to individuals and their defense and coping mechanisms, which could lead to improved therapy use and compliance.
\end{abstract}

Keywords Veterans · Former soldiers · Trauma · Coping · PTSD · Defense · GAF · Qualitative survey

\section{Introduction}

\section{The Situation of a Former German Soldier in an International Comparison}

In all, 85.5\% of the German Armed Forces' (GAF) foreign missions are associated with the experience of stressful events and an increased prevalence of mental illness with a

\section{Loni Brants}

loni.brants@charite.de

1 Department of Psychiatry and Psychotherapy, Campus Charité Mitte, Charité -

Universitätsmedizin Berlin, corporate member of the Freie Universität Berlin,

Humboldt-Universität zu Berlin, and Berlin Institute of Health, Charitéplatz 1, 10117 Berlin,

Germany

2 Psychotraumazentrum, Military Hospital, 10115 Berlin, Germany 
generally low level of therapy use (Wittchen et al. 2012). In addition to traumatizing events during their missions abroad and experiences of discrimination at home due to their careers, (former) soldiers in general have to manage high amounts of stress and adjustment. Different demands (assimilating into the military system, war experiences abroad, return and reintegration into professional and family life afterwards, leaving the military, reintegration into civilian life and perhaps dealing with symptoms of a traumarelated disorder) require an extremely high degree of adaptability (Schuy et al. 2018, Brants et al. 2018). In contrast to the broad state of knowledge about the mental health of, for example, US soldiers, little is known about the handling of stressful events and mental illness among active GAF soldiers (Kowalski et al. 2012), and even less is known about the coping of former GAF soldiers who have left the military system (Siegel et al. 2017). For various reasons, it is not possible to easily apply international findings to the situation in Germany, not least because of diverging national sociocultural factors and different benefits laws. The attitudes of the German public to military forces in general, and the GAF in particular, are still influenced by Nazi history and the war crimes of the German Wehrmacht. Therefore, active and former German soldiers, especially mentally ill soldiers, are exposed to high levels of stigmatization, which they have to cope with in their everyday life and which makes it even more difficult to seek professional help (Schuy et al. 2018). However, even in countries such as the USA, where traumatization of soldiers and their (subsequent) coping mechanisms have been the focus of scientific and societal attention for some time now, to our knowledge, there are hardly any studies or publications on the defense and coping mechanisms of former soldiers.

\section{Coping and Defense Mechanisms}

Beutel (1990) defines coping mechanisms as mostly conscious, not automatic, cognitive and experience-related or behavioural processes in persisting, aversive situations or situations expected to become aversive. Since the development of the transactional stress model by Lazarus and his colleagues (Lazarus and Launier 1981; Lazarus and Folkman 1984), coping mechanisms have become the subject of intensive psychological research (Overview: (Schwarzer 1998)). The subsequently developed category systems and instruments, such as the COPE (Kato 2015; Carver et al. 1989), made it possible to discover coping mechanisms through self-disclosure and to develop first coping concepts. However, the role of individual personality traits and (biographical) motives was often neglected in those coping concepts and scales (Steffens and Kächele 1988). Lazarus himself admitted that unconscious intentions were hardly represented in this approach (Lazarus 2000). Although research results in recent years support a high proportion of unconscious, intuitive processes, especially in complex, fast decisions (Horr et al. 2014; Gigerenzer and Kober 2009), in this respect little has changed in the approach to coping research to our knowledge.

During the last decades, the research on defense mechanisms has grown immensely. Psychoanalysts from different schools interpret defense differently, and every definition involves the risk of an over-reduction of this very complex construct. In their 600-page book on the current state of theory and research of defense mechanisms, Hentschel et al. (2004) rightly stress the complexity of the subject. They also acknowledge the often divergent attitudes to psychoanalysis in general and to defense mechanisms in 
particular of the psychological research field. According to Beutel, defense mechanisms can be understood as unconscious, primarily cognitive and experience-related processes that include a narrowing or distortion of intersubjective reality and self-perception (Beutel 1990). After the development of Sigmund Freud's theory of defense, its further development by his daughter Anna Freud and the publication of her work 'Ego and the Mechanisms of Defense' (Freud 1936), the concept of defense was supplemented by intrapsychological and interpersonal perspectives of the various currents within the school of psychoanalysis. In recent decades, authors such as Vaillant, Laughlin and König have repeatedly attempted to develop and introduce a new kind of taxonomy, but the number and classification of the chosen defense mechanisms differed considerably from author to author (Vaillant 1971, 1992; Laughlin 1979; König 1997; SeiffgeKrenke et al. 2017). In addition, the concept of the individual's psychic structure has become increasingly important in theory, in the context of operationalized psychodynamic diagnostics (OPD) (Cierpka et al. 2007; Cierpka 2014), as well as in psychotherapeutic and trauma therapy practice (Rudolf et al. 2004; Wöller 2013).

There seems to be relative agreement that defense and coping mechanisms have or are Ego-functions, with defense being used for inner-psychic protection and regulation and coping for real adaptation and problem solving (Steffens and Kächele 1988). In other words, only the corresponding (unconscious) defense enables successful (conscious) coping (Cierpka 2014).

In psychoanalytic theory and research certain character types (König 2004) and clinical diagnoses are associated with certain constellations of defense and coping mechanisms, for example the obsessive-compulsive disorder with reaction formation and isolation (Rubino et al., 2007) or the borderline personality disorder with mechanisms such as sensation seeking, autoaggressive behaviour, dissociation, splitting and many more. In recent decades, numerous well-known authors have repeatedly expressed criticism of an explicit separation of coping and defense (Cierpka 2014; Steffens and Kächele 1988; Beutel 1990). Steffens \& Kächele already wrote in 1988: "We consider it sensible to give up a strict separation of coping and defense. Both processes complement each other, by no means exclude each other alternatively". Nevertheless, in the past, there were repeated "denial efforts of kinship relations" in both concepts (Cierpka 2014; Steffens and Kächele 1988; Beutel 1990). Even now, at least in Germany, the use of either coping self-rating scales in clinical psychiatric practice and science, on the one hand, and the focus on unconscious conflicts and defense mechanisms of psychoanalytic therapists and scientists, on the other hand, indicate a continued one-sided approach. To our knowledge, there has been no practical, integrative model for the identification and representation of coping and defense mechanisms in trauma-related disorders. This deficiency is surprising since coping mechanisms (such as sports or drug consumption) and/or unconscious defense mechanisms (e.g., rationalization or splitting) play an important role in diagnosis, therapy planning and prognostic assessment by therapists of different schools. This role is especially true for patients with trauma-related disorders, in whose treatment Egosupporting, affect-regulating interventions are often of great practical importance.

In general, active coping (e.g., fight or flight) is more likely to be used if the person assumes he/she can control the threat or escape from it. If the individual considers control or escape impossible, he/she usually reacts with passive mechanisms (Olff and Langeland 2005). It was, therefore, assumed that the use of certain coping mechanisms 
was primarily situation-dependent. On the other hand, there are also indications that a certain coping style or the repetitive use of certain mechanisms can represent a risk factor in the development of trauma-related disorders (Chang et al. 2003). This risk corresponds to the psychoanalytical assumption of a 'defense and coping profile' linked to the psychological structure and to findings from current trauma research indicating that an individual's coping style or coping mode influences whether the affected person can successfully handle the traumatic experience or develops a mental illness such as PTSD (Chang et al. 2003; Johnsen et al. 2002).

\section{Goal of this Study}

Apart from a phenomenological description of coping and defense mechanisms, this study aims to determine if there are specific combinations of mechanisms that lead to special adjustment types among former GAF soldiers and their approach to psychotherapeutic or psychiatric treatment.

\section{Method}

\section{Research Context}

This study was conducted within the framework of the "German former soldiers' Readjustment Study", which is a research project designed to gain insight into the daily life of former German soldiers, including their life satisfaction, economic situation, family situation and their health status. It was approved by the ethics committee of the Charité Universitatsmedizin Berlin (Approval Number EA1/250/14).

\section{Recruitment and Sampling}

Recruiting potential participants took place via a project-owned website and the psychiatric ward of the GAF Hospital Berlin. Former soldiers of the GAF who had participated in at least one foreign assignment were included. Thus, it was possible to identify 103 potential participants, of whom five could not ultimately be contacted. Short telephone interviews were conducted with the remaining 98 participants. They were asked about their motivation for participating and to provide their sociodemographic data. The inclusion criteria were checked as well. In all, 43 of the remaining 98 participants were eventually invited to phase two of the project, the open interviews. The participants were initially selected at the Bundeswehr hospital in Berlin using opportunistic sampling (Teddlie and Yu 2007). Because theoretical saturation arose during the course of the interviews and the initial analysis, other interview partners not associated with the hospital were selected, visited and interviewed in their homes. For this purpose, participants with and without psychological symptoms and those who did or did not use psychosocial services were selected to create a contrasting sample (based on the theoretical sampling of Strauss and Corbin (Corbin and Strauss 2008)) and to achieve the highest possible degree of variation. Each interview was promptly followed by a debriefing session with the research team. Form, situation, content and countertransference experience were compared with previous interviews, 
and the next procedure was determined, especially with regard to sampling. After a total of 43 interviews, we reached theoretical saturation, which eventually led to the cessation of data collection.

We then subjected 16 interviews, again selected on the basis of contrasting features (origin, age, gender, relationship status, number of children, training level, military rank and organizational area, country of mission, duration of deployment, psychological symptom burden, psychotherapy experience, and claim of service-incurred disability), to a detailed thematic analysis and compared the resulting concepts with the remaining 27 interviews.

\section{Participants}

The included sample comprised former soldiers of different ranks (from soldiers to senior officers), organizational units (Army, Navy, Air Force, Joint Support Service, and Central Medical Service) and federal states of Germany (12 out of 16). Four (9.3\%) participants were female; the age span of the participants was between 26 and 69 $(\mathrm{MW}=40.4 ; \mathrm{SD}=12.3)$. Some participants had just left the GAF, and others had been civilians for several years. According to the former soldiers interviewed, 19 (44\%) suffered from a service-incurred disability, and three $(6.9 \%)$ were in treatment time, which is a time span used for clinical and occupational rehabilitation in Germany during which soldiers, although not on active duty, cannot be discharged from military service.

\section{Data Collection}

The data were collected in personal, open interviews. The interviews were conducted jointly by two of the authors, with one of them moderating the discussion and the other responsible for the equipment and accompanying field observations. This also included his/her own counter-transference experience and observations of emotional reactions of the interviewees and in some cases, for example, their interaction with relatives or partly present pets, etc.

During the interviews, the researchers used a narrative technique (Küsters 2014) that always started with a general introduction about the former soldiers' experiences and their adjustment in the GAF before, during, and after their deployment, as well as after their discharge and today. The interviewers let the participants talk about whatever seemed to be significant to the participants. If inconsistencies occurred, or if emotional responses were displayed, or if challenging situations were described, the interviewer encouraged the participants to elaborate more deeply on the emerging issues, especially with regard to conscious and unconscious mechanisms to adjust. The interviews were finished when the participants had nothing left to describe. Conscious coping mechanisms (e.g., alcohol consumption, sport) were reported during the interview, sometimes without being asked and sometimes directly asked at a later point in time. Unconscious coping and defense mechanisms were identified in the very detailed descriptions of the participant's situation and action processes (e.g., rationalization, denial) or observed during the interview (e.g., affect isolation, dissociation). The entire interview was recorded in MP3 format and then transcribed by an external transcription service pledged to confidentiality (Dresing et al. 2015). 


\section{Data Analysis}

The methodological analysis process based on the principles of grounded theory and thematic analysis involved the iterative generation of hypotheses and the development of new models and typologies. According to Chapman et al. 2015, we also approached the material iteratively through inductive development, deduction and validation to develop a theoretical model anchored in the material, whereby the data collection and analysis processes were continued until saturation occurred, which is when no new insights result from data collection and analysis. Our approach corresponded to the steps mentioned by Guest et al.: 1. getting to know the material, 2. identifying thematic categories, 3. identifying structures and combinations and 4. building a theoretical model based on the findings (Guest et al. 2012).

The first step consisted of getting to know the material by repeatedly listening to the interviews, reading the transcripts and making notes and cross-references using the MAXQDA12 program. First codes were given to note down or summarize the observed or otherwise identified coping and defense mechanisms. For example, a passage in which an interviewee described how he cried during psychological sessions was given the code "crying" (along with others). In the second step, thematic categories were identified by combining, contrasting and merging similar or interconnected coping and defense mechanism codes. For example, the code "crying" was then combined with other codes such as "expressing sadness or anger" or "showing feelings", and the category "show emotions" was created. The third step included the review and analysis of the thematic categories found to identify underlying thematic structures, motifs, functions or specific combinations of coping and defense categories using new raw data from the ongoing data collection and analysis. To continue illustrating with the above example, the passages and codes were read again, the codes were compared, and the intensity and context in which emotions were shown or not shown were examined or other codes with emotional content were added to the category. The fourth and final step was to develop a typology based on the combinations of mechanisms found in the material, constantly cross-checking it with new material and also including current literature and existing models. Thus, for example, different manifestations of the area "emotion" arose and a model continuum with the superordinate area "emotion" was created, consisting of the three emotion categories "defensive", "partially permissive" and "affirmative" (Tables 1 and 2).

For further verification and differentiation of our results, we used the "Document Portrait" function of the MAXQDA program, which is a tool for visualizing an interview by representing it as an image of its codes. The frequency and length of the coded defense and coping mechanisms within the conversation are displayed as a graphical representation, whereby the length of a segment is taken into account and included as a weighting factor for the graphical representation. The result of the preceding steps was the development of a typological classification, which we have summarized in the form of results tables for better representability (Tables 3-9).

\section{Quality Assurance}

To ensure the highest possible quality during the scientific process, qualitative research was conducted in accordance with qualitative research quality criteria (Stamer et al. 


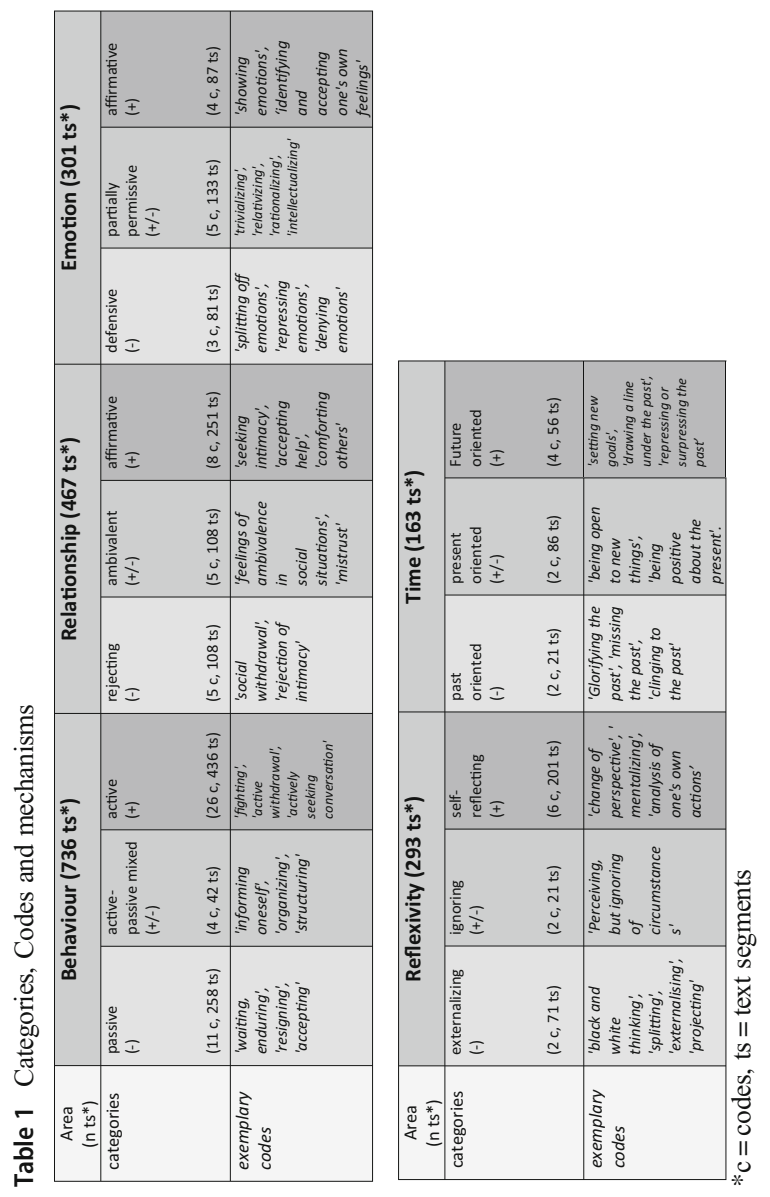


Table 2 Identified coping and defense areas

\begin{tabular}{|c|c|c|c|}
\hline Area & \multicolumn{3}{|c|}{ Behaviour } \\
\hline $\begin{array}{l}\text { Categories and } \\
\text { Gradations }\end{array}$ & $\begin{array}{c}\text { passive (-) } \\
\text { e.g., enduring }\end{array}$ & active-passive mixed (+/-) & $\begin{array}{c}\text { active (+) } \\
\text { e.g., attacking }\end{array}$ \\
\hline Area & \multicolumn{3}{|c|}{ Relationship } \\
\hline $\begin{array}{l}\text { Categories and } \\
\text { Gradations }\end{array}$ & $\begin{array}{c}\text { rejecting (-) } \\
\text { e.g., social retreat }\end{array}$ & ambivalent (+/-) & $\begin{array}{l}\text { affirmative (+) } \\
\text { e.g., intensive search } \\
\text { for intimacy }\end{array}$ \\
\hline Area & \multicolumn{3}{|c|}{ Emotion } \\
\hline $\begin{array}{l}\text { Categories and } \\
\text { Gradations }\end{array}$ & $\begin{array}{c}\text { defensive (-) } \\
\text { e.g., splitting off } \\
\text { feelings }\end{array}$ & partially permissive (+/-) & $\begin{array}{l}\text { affirmative (+) } \\
\text { e.g., answering } \\
\text { affectively }\end{array}$ \\
\hline Area & \multicolumn{3}{|c|}{ Reflexivity } \\
\hline $\begin{array}{l}\text { Categories and } \\
\text { Gradations }\end{array}$ & $\begin{array}{l}\text { externalizing (-) } \\
\text { e.g., projection }\end{array}$ & ignoring (+/-) & $\begin{array}{c}\text { self-reflecting (+) } \\
\text { e.g., analysis of own } \\
\text { feelings and actions }\end{array}$ \\
\hline Area & \multicolumn{3}{|c|}{ Time } \\
\hline $\begin{array}{l}\text { Categories and } \\
\text { Gradations }\end{array}$ & $\begin{array}{l}\text { past-oriented (-) } \\
\text { e.g., glorifying the } \\
\text { past }\end{array}$ & present oriented (+/-) & $\begin{array}{l}\text { future-oriented (+) } \\
\text { e.g., focusing on new } \\
\text { plans for the future }\end{array}$ \\
\hline
\end{tabular}

2015). In addition to the previously mentioned theory-based, iterative approach to sampling and data collection, analysis and verification, we also chose a multi-perspective, multidisciplinary research team (doctors and psychologists with and without clinical experience and with and without military background or deployment experience abroad). The validation processes in the research group, in particular, proved to be a very important element for the conscious, reflexive, flexible and self-critical handling of the data and team members' pre-concepts. In addition to the internal communicative validation by presentation of the (partial) results and discussion of (partial) results and corrective consensus-building, all project members committed themselves to regular participation in advanced training and external research workshops and to external research supervision.

\section{Results}

Overall, a very large number and range of described, named and observed defense and coping mechanisms were found in the group we interviewed as well as in the individual interviews. Thus, in the first step of thematic analysis (according to Guest et al. (2012) and Chapman et al. (2015)), we extracted a total of 1960 text segments containing forms of conscious and unconscious coping and defense mechanisms, which were ordered in 89 codes. In the second analysis step, these codes were categorized 
according to their content, motif and function and assigned to 15 superordinate coping and defense categories (See Table 1).

In the third step, the examination and analysis of the categories found to identify underlying thematic structures and combinations, the existing 15 coping and defense categories were reduced to the five overarching thematic areas of 'behaviour', 'relationship', 'emotion', 'reflexivity' and 'time', whereby each area could be divided into three value-neutral gradations $(-, \pm$ and + ) (See Table 2$)$.

In the fourth step, theoretical assumptions were compared with the newly found data and coping/defense modes and combinations were identified and verified using the 'portrait function' (see: Data analysis) and integrated into a prototypical classification (See Tables 3-9).

Although most former soldiers showed a large variety of different coping and defense mechanisms, many of the interviewees used a repetitive pattern of individual core mechanisms at different stages of adaptation. Analysing the combination, frequency and dominance of use of certain coping mechanisms in the investigated sample, seven distinguishable defense and coping types with special coping modes could be

Tables 3 Prototypical classification

\section{Fighter (Fighting Mode)}

The Fighter takes matters into his own hands. He sets himself new goals and tasks, and he diverts himself with activities. He actively avoids aversive situations and sets clear boundaries. He describes situations focusing on his actions and behaviour and is capable of self-reflection. He tries to avoid deeply emotional involvement (by rationalizing, trivializing or disciplining himself). Human relationships and closeness are seen positively. His time-related foci are present and future; his contextual foci are capacity, power and performance.

\begin{tabular}{|l|l|}
\hline Behaviour: & ++ \\
\hline Relationship \& Bonding: & + \\
\hline Emotion: & $+/-$ \\
\hline Reflexivity: & $+/-$ \\
\hline Time Focus: & + \\
\hline Strengths: & $\begin{array}{l}\text { Proactive targeted behaviour, willpower, } \\
\text { ambition, future-orientated perspective }\end{array}$ \\
\hline Weaknesses: & $\begin{array}{l}\text { Little emotional access, little ability to calm } \\
\text { down and relax, difficulties accepting/seeking } \\
\text { help because of unawareness of own emotional } \\
\text { and physical boundaries. }\end{array}$ \\
\hline Opportunities: & $\begin{array}{l}\text { If he himself makes the decision to go into } \\
\text { therapy, he will show great commitment and } \\
\text { compliance. }\end{array}$ \\
\hline Risks: & $\begin{array}{l}\text { Decompensation because of extreme dedication } \\
\text { to performance and discipline to the point of } \\
\text { total exhaustion. }\end{array}$ \\
\hline
\end{tabular}

Quotation: "I can only ask my soldiers to do what I do and to set an example for them. For example, when I was in the camp with my soldiers, I always told them, 'First the equipment and then it's your turn.' And I have to set an example.' (...) We were still drudging when we were inside [in the camp], because we/ basically we came in, we ate something, had a drink, took a shower, stocked up our kits, fixed everything, in order to basically set out three or four days later.(...) And to keep the motivation up and say: 'We're going out again now.', honestly, to me, the guy who says, 'Yeah, we're going out there again', is a soldier. Because he could just stay [in the camp] as well and claim, 'Oh, I'm ill."' 
Tables 4 Prototypical classification

\section{Strategist (Active-reflexive Mode)}

The Strategist acts on his own initiative. He looks on his own for prospective alternatives, makes his own decisions, is aware of inner changes since his mission abroad, intensively reflects on the past and the world of today. He can perceive and identify his emotions to a certain extent. He has a positive approach to relationships as long as he remains fairly independent. His time-related foci are present-time and future; his contextual foci are positive aspects of the present and plans for the future, his self-efficacy and positively experienced solution strategies.

\begin{tabular}{|l|l|}
\hline Behaviour: & ++ \\
\hline Relationship \& Bonding: & + - \\
\hline Emotion: & + \\
\hline Reflexivity: & ++ \\
\hline Time Focus: & $\begin{array}{l}\text { Good self-efficacy, self-reflection and awareness } \\
\text { of his own behaviour and feelings; good ability } \\
\text { to overcome difficulties and to understand } \\
\text { possible symptoms on a cognitive level in terms } \\
\text { of cause or function. }\end{array}$ \\
\hline Weaknesses: & $\begin{array}{l}\text { Little awareness of necessity for professional } \\
\text { help due to his high level/need of autonomy and } \\
\text { his cognitive abilities. }\end{array}$ \\
\hline Opportunities: & $\begin{array}{l}\text { Getting, experiencing and accepting help from } \\
\text { others; understanding and lowering his high } \\
\text { personal and professional demands }\end{array}$ \\
\hline Risks: & $\begin{array}{l}\text { Refusal of treatment and hence mental and } \\
\text { physical overload because of high personal } \\
\text { demands. Personal stagnation. }\end{array}$ \\
\hline
\end{tabular}

Quotation: "And the only good thing is that I said, 'Yes, I want to study again, I'm doing something for my brain again.' Right? And the others just got ready for working life there, but the psychologist who was there really pulled me out of my military life. And I also cried every night, I cried there EVERY night. I cried my eyes out. And there were two seminars, there was a German seminar and the same again in English with native speakers and so it was super demanding (..) That helped me a lot, because I found the courage to reorient myself."

identified: the Fighter, the Strategist, the Partisan, the Self-Protector, the Infantryman, the Comrade and the Corpsman, whereby the last can be seen as a subtype of the Comrade. The following tables describe the various subtypes according to their prototypical traits, expressions and modes (Tables 3-9), whereby the strengths, weaknesses, risks and opportunities of the types were clarified according to the principle of SWOT-analysis. A sample quote from an interview with a participant assigned to the corresponding type, translated from German, is intended to serve as clarification. For ease of readability, the masculine form is used in the following description. However, the descriptions apply to both sexes.

\section{Discussion}

\section{Reflexions and Interpersonal Aspects}

When we launched our website, we anticipated a moderate response. This turned out to be a mistake. After just one week, the call to participate in the study had been shared 
Tables 5 Prototypical classification

\section{3.a Comrade (Social Mode)}

The Comrade puts emphasis on comradeship and his social role, stays in touch with his former comrades or creates a new social network (family, friends, animals). Loyalty to his peer group is highly important to him. He describes situations with emphasis on social experiences. His ability to reflect on himself is reasonable to good, but he avoids or denies emotions when they are different from those of his surroundings. His time-related focus is rather indifferent, and his contextual foci are comradeship and his social surrounding.

\begin{tabular}{|l|l|}
\hline Behaviour: & + \\
\hline Relationship \& Bonding: & ++ \\
\hline Emotion: & - \\
\hline Reflexivity: & + \\
\hline Strengths: & $\begin{array}{l}\text { Gains strength from social involvement, great } \\
\text { ability to communicate, to create, bear and } \\
\text { enjoy closeness and to carry responsibility for his } \\
\text { comrades and family. }\end{array}$ \\
\hline Weaknesses: & $\begin{array}{l}\text { Loyalty conflicts when his interests are at } \\
\text { variance from those around him; fear of loss of } \\
\text { social prestige/reputation if illseeking } \\
\text { professional help. }\end{array}$ \\
\hline Opportunities: & $\begin{array}{l}\text { Understanding and accepting own interests, } \\
\text { desires and needs; valuable member in social } \\
\text { framework. }\end{array}$ \\
\hline Risks: & $\begin{array}{l}\text { Decompensation/loneliness through/due to loss } \\
\text { of "GAF-Family" }\end{array}$ \\
\hline
\end{tabular}

Quotation: "It's never addressed when you might have hoped for more help in the conversation, for example, that you would be able to get rid of this burden during a conversation for example, that's not provided by the family. I get more help from my comrades. And when I compare this/ that comradeship of '99, from the first assignment, and a good ten years later, I mean, there is a difference as day and night. And this camaraderie, which we lived in '99, is no longer the camaraderie demonstrated in 2009, 2010. (...) Today I still have contact with colleagues and comrades from '99, which I am very proud of. Because they're really people, I can call them now, they come here and I don't want to say 'they do something', but they're there for you. (...) This has been a big, big, negative step in the German Armed Forces. In the meantime, we have become just service providers. And the troop as such, as it was once, no longer exists."

over 28,000 times. We had underestimated the veterans' need to communicate and their feeling of not being seen in their suffering. This impression was strenghtened in the further work process. The fact that the members of our research group were part of a well-known non-military university institution but still had military knowledge and in part military experience themselves certainly contributed to greater openness in the interviews.

When we asked the potential interviewees in preliminary telephone interviews about their motivation to talk to us, we often heard answers like: "Finally there's someone listening", "For me, participating in this project is the first step in dealing with what I have experienced", or "Participation is the chance that something finally changes. Most people don't dare to speak." The great expectations of us and our project motivated us, but the idealization in some of those answers also made us afraid to disappoint those needs and hopes. 
Tables 6 Prototypical classification

\section{3.b Corpsman (Altruistic Mode, Subtype of the Social Mode)}

The Corpsman is a person who is very committed to helping and supporting others, but who represses, trivializes or denies his own desires, needs and feelings. In his stories, he emphasizes other people's pain and his role as a helper. He has moderate self-reflection abilities, but he represses or denies his own feelings and is not aware of his limitations. His time-related focus is the present time, and his contextual foci are other people's misery and suffering.

\begin{tabular}{|l|l|}
\hline Behaviour: & $+/-$ \\
\hline Relationship \& Bonding: & ++ \\
\hline Emotion: & - \\
\hline Reflexivity: & $+/-$ \\
\hline Time Focus: & $+/-$ \\
\hline Strengths: & $\begin{array}{l}\text { Gains confidence and self-esteem by supporting, } \\
\text { helping and caring for others. Valuable member of } \\
\text { social framework. }\end{array}$ \\
\hline Weaknesses: & $\begin{array}{l}\text { Self-esteem and psychological stability by caring for } \\
\text { others; no awareness of own needs or that he } \\
\text { subordinates them to other people's desires. }\end{array}$ \\
\hline Risks: & $\begin{array}{l}\text { Understanding and accepting own needs and desires, } \\
\text { increasing autonomy. }\end{array}$ \\
\hline
\end{tabular}

Quotation: "I just didn't want to give up; I can't just leave because of the mother of XX and XX. I think they would collapse if they didn't have my support now. And when I say, 'I can't do it anymore! I'll just leave it!', then the house of cards collapses. And I know I'm just standing and holding on tight."(sighs heavily)

The interviews showed a very detailed descriptions of the behaviour and activities of the former soldiers at home and abroad. In contrast, hardly any of the interviewees spoke much about their emotional experiences. When feelings were shown openly, this often happened in the form of hardly regulated emotional reactions. The question of whether this phenomenon is a group characteristic or a symptom of trauma disorder (in the sense of emotional numbness or flooding) cannot be answered with absolute certainty. Our analysis showed that some emotions such as disappointment, anger and bitterness were frequently addressed and named, while others, such as sadness, guilt, shame and fear were hardly expressed or mentioned. One possible interpretation of this discrepancy could be that feelings such as disappointment, anger and bitterness were often directed to the external military or civil system and are also better compatible with the soldiers' self-standard (Schuy et al. 2019). Sadness, fear or shame, on the other hand, might be feelings that are less compatible with this ideal and therefore had to be fended off unconsciously or were deliberately concealed from us. This leads to the assumption that, regardless of posttraumatic symptoms, there may be a special degree of conscious and unconscious rejection of emotions within our group.

We also have to acknowledge that the respective military rank may have an influence on the mechanisms and behaviours described. Types such as the infanteryman, for example, are likely to be less frequent and less long-term in leading positions, while types such as the strategist are more likely to feel comfortable in a 
leadership position on account of his need for autonomy as well as his abilities. However, these interactions certainly also exist in the civilian field.

\section{Classification of the Results}

The typology presented here is a first classification attempt based on the data material to illustrate an integrative approach linking schools and approaches to psychotherapy to be able to make an initial assessment of the conscious and unconscious coping abilities, strengths, weaknesses and psychotherapeutic needs of former GAF soldiers within the

Tables 7 Prototypical classification

\section{Partisan (Aggressive Mode)}

The Partisan is in a fight against the military system, his country and civil society. He describes situations focusing on his actions and behaviour (oscillating between attack and resignation). His ability for self-reflection and mentalizing is poor, he represses or denies emotions despite hate and anger, projects inner feelings or conflicts onto his surrounding, rejects closeness and relationships, and focuses on his past. His contextual focus is on the failure of others.

\begin{tabular}{|l|l|}
\hline Behaviour: & + and - \\
\hline Relationship \& Bonding: & -- \\
\hline Emotion: & - \\
\hline Reflexivity: & -- \\
\hline Strengths: & - \\
\hline Weaknesses: & $\begin{array}{l}\text { Ability and will-power to speak up for his rights } \\
\text { and goals and to fight against perceived } \\
\text { injustice. Ability to feel and reveal } \\
\text { disappointment and anger. }\end{array}$ \\
\hline Opportunities: & $\begin{array}{l}\text { Low ability to change perspective, to mentalize } \\
\text { and to reflect on himself. Social needs or a } \\
\text { desire for closeness are drastically rejected by } \\
\text { externalization, splitting and devaluing others. } \\
\text { Poor awareness of emotions other than hate } \\
\text { and anger. Little impulse control. }\end{array}$ \\
\hline Risks: & $\begin{array}{l}\text { Becoming aware of his own responsibility. } \\
\text { Admitting a desire for relationships. Recognizing } \\
\text { and accepting his repressed sensitivity and } \\
\text { vulnerability. }\end{array}$ \\
\hline "And
\end{tabular}

"And boom (...) back in XX again, I thought I wanted to shoot myself, right? (...) Just stupid, idiot, indifferent people who didn't give a shit anyway, right? And, (...) yeah, you couldn't tell people anything, could you? Either they didn't believe it anyway, or they didn't want to know. And I said 'good'. And as I said, it's still going on today, those people out there just make me sick. (...) Just sick. This whole system, this/(...)"

"But that was ten years ago, right?"

"(...) That still pisses me off today. I'd still prefer to be by myself. Right? That starts with looking for a job. You'll get screwed. You'll get fucked over on the job. Even in a group of co-workers, you're already messed with, aren't you? Like, I don't know, "Yes, I'll come by tomorrow morning, and then I'll pick you up and then we'll go/" Yes, pff. And then it's tomorrow and the colleague doesn't come, doesn't answer and nothing at all and three weeks later, "Oh yes, I forgot." Yes, thank you very much. Right?" 
Tables 8 Prototypical classification

\begin{tabular}{|c|c|}
\hline \multicolumn{2}{|c|}{$\begin{array}{l}\text { 5. Self-Protector (Negating Mode) } \\
\text { The Self-Protector is constantly trying to escape from difficult situations and the respective } \\
\text { emotions, either through passive avoidance mechanisms, such as intellectualizing, rationalizing, } \\
\text { trivializing, repressing or denying negative feelings and implementing high safety precautions, or } \\
\text { through active avoidance mechanisms, such as flight, professional over-commitment and other } \\
\text { means of distraction. He approves of relationships to a certain extent but struggles with self- } \\
\text { reflection and deep emotional experiences and involvement. His time-related focus is on the } \\
\text { present and future, and his contextual foci are on his activities, self-protecting acts, and } \\
\text { psychosomatic complaints. }\end{array}$} \\
\hline \\
\hline \multicolumn{2}{|c|}{\begin{tabular}{l|l} 
Behaviour: & + and - \\
Relationship \& Bonding: & + /-
\end{tabular}} \\
\hline \multicolumn{2}{|l|}{ Emotion: } \\
\hline \multicolumn{2}{|l|}{ Reflexivity: } \\
\hline \multicolumn{2}{|l|}{ Time Focus: } \\
\hline Strengths: & $\begin{array}{l}\text { Good defense mechanisms if problems are mild } \\
\text { because needs and desire for protection and } \\
\text { flight can be answered promptly. }\end{array}$ \\
\hline Weaknesses: & $\begin{array}{l}\text { Avoidance of self-reflection. Negatively } \\
\text { experienced feelings must be fended off with all } \\
\text { means, little willingness to introspect. }\end{array}$ \\
\hline Opportunities: & $\begin{array}{l}\text { Improvement of his own emotional approach, } \\
\text { reduction of anxiety, tension and psychosomatic } \\
\text { reactions. }\end{array}$ \\
\hline Risks: & $\begin{array}{l}\text { Prolonged avoidance of therapy despite severe, } \\
\text { mostly psychosomatic symptoms. }\end{array}$ \\
\hline
\end{tabular}

Quotation: "And at some point, I was transferred to a unit in XX (...). And during my service there/ it started shortly after I had just started, it started with abdominal/stomach cramps/belly cramps and I had to vomit constantly. During daytime SERVICE, it was getting harder and harder. And one day I was taken to the Bundeswehr hospital in XX to be examined. And after I had been there for about eight weeks or so - I don't know exactly - six/six or eight weeks, I think, they tried to find real causes during this time. They didn't find ANYTHING."

"Yeah, I don't want to be reminded of it all the time. I'm constantly reminded of it at night, that's enough for me! I don't want to walk around so fidgety all day. So I'm avoiding that, right, I'm trying to avoid that I/ (...) get NERVOUS, start sweating and trembling and, yeah, that's not so great."

course of diagnostic conversations without the use of further questionnaires and independent of the psychotherapeutic background of the diagnostician.

The great individual variability in coping and defense mechanisms used by former soldiers at different points in time confirms the frequently cited thesis that the situation and the perceived threat influence an individual's choice of coping mechanisms, whereby a simultaneous use of different mechanisms usually occurs (Olff and Langeland 2005). On the other hand, we have been able to identify recurring, often unconscious, core mechanisms in individual participants, which were used at several points of time. This consistency speaks to their cross-situational use. This consistency corresponds to the psychoanalytical assumption of a 'defense profile' linked to the psychological structure and to findings of current trauma research indicating that the individual coping style influences whether a person successfully processes a trauma in the long term or develops a trauma-related disorder (Chang et al. 2003; Johnsen et al. 2002). 
Tables 9 Prototypical classification

\section{Infantryman (Accepting Mode)}

The Infantryman is capable of accepting difficult situations and adapting to changing circumstances. He executes the given commands reliably and can set aside inner conflicts. His self-reflection and emotional experience are diminished/rejected, his time-related focus is present-oriented, and his contextual foci are his (passive) behaviour, the command situation and his execution of orders.

\begin{tabular}{|l|l|}
\hline Behaviour: & -- \\
\hline Relationship \& Bonding: & $+/-$ \\
\hline Emotion: & - \\
\hline Reflexivity: & - \\
\hline Time Focus: & + \\
\hline Strengths: & $\begin{array}{l}\text { Ability to withstand difficult situations for a long } \\
\text { time and accept and make the best of them. }\end{array}$ \\
\hline Weaknesses: & $\begin{array}{l}\text { Little awareness of his own needs, and therefore } \\
\text { little commitment to stand up for himself. }\end{array}$ \\
\hline Opportunities: & $\begin{array}{l}\text { Perceiving his own limits and needs; learning to } \\
\text { take responsibility; gaining more control over his } \\
\text { life. Good willingness to enter therapy if } \\
\text { "instruction" comes from the outside. }\end{array}$ \\
\hline Risks: & $\begin{array}{l}\text { Long latency until the use of assistance without } \\
\text { clear instructions or gatekeeper; no claim/use of } \\
\text { medical/psychological services at all. }\end{array}$ \\
\hline
\end{tabular}

Quotation: "I was very lucky to have a friend in my circle of friends who worked here at Bundeswehr Hospital as a doctor, when I started feeling bad two years ago, and he said: 'This is not just about your normal life, which you've been living up to now, with all its difficulties, but you are still carrying around a lot of things from before that you haven't processed yet.' And he took me by the hand and brought me here, so to speak, and then I was tested here, and then they said to me: "Yes, there's something wrong here. We have to work on it." Well, if this guy hadn't been there, I wouldn't be here. (...) Well, because I had to be led to it first. (...) I was dismissed from my position at that time on the condition not to talk about my assignment abroad. And that's why l've been silent about it for almost 20 years, and I simply wrote it off as experience. And I was / At that time, one was silenced under threat of punishment, which I find very wrong today. But I can also understand the political background or the motivation for it being that way. And as I said, if I didn't have my friend and comrade, who said, 'You can talk about it. We'll go there. There's help. Otherwise I wouldn't be here."'

Overlaps of psychoanalytic character types and structures (e.g., König 2004) with the types introduced in this article can be seen. There are also similarities to coping concepts such as the classification of COPE (Carver et al. 1989). However, both are closely associated to specific schools of psychology and therefore are often interpreted within the respective theoretical framework. Our aim was to use an unbiased and open approach to this topic to detect underlying patterns which are not automatically associated with an existing theoretical framework and therefore enable the integration of different perspectives. Therefore, the examination of existing theoretical backgrounds took place at a rather late point in time and involved more the comparison or exploration of similarities and differences.

Revealing unconscious mechanisms requires a personal interview situation, and an external view is absolutely necessary. The research results of the last few years 
underscore the high proportion of unconscious, intuitively functioning processes, especially in the case of complex, fast-track decisions (Horr et al. 2014). It is virtually impossible to record such processes by filling in self-rating scales, such as coping scales such as the COPE (Carver et al. 1989). In fact, only on the basis of our interview approach were we able to identify additional mechanisms, to differentiate more precisely between emotional and reflexive reactions and to recognize the motives, gradations and characteristics of relationships, emotional approval, or reflexivity. Only in the context of conversations could motives be identified and coping mechanisms be detected and strictly assigned to the corresponding specific categories and modes.

Despite scientifically well-investigated and effective therapy methods, it is wellknown that only a small percentage of (former) soldiers with mental illnesses use psychosocial services in the USA, Great Britain and Germany (Hoge et al. 2004; Stecker et al. 2007; Murphy and Busuttil 2015; Iversen et al. 2010; Siegel et al., 2017), and many wait for years to decades before entering treatment (Sayer et al. 2009; Sayer et al. 2004; Wang et al. 2005; Sayer et al. 2007). Even if they see a doctor, many evidence-based treatment options that work in other clinical contexts often seem to fail in this specific context. One reason may be that members of the military system have different basic assumptions about mental illness and psychotherapeutic treatment from civilian patients. The conflict of identity that arises in the soldier from the implicit weakness of the mental illness and the fear of stigmatization may be even greater than in members of civilian society (Schuy et al. 2018).

Rüsch et al. also emphasized the relevance of fear and experience of stigmatization and discrimination among soldiers in their qualitative work on the self-revelation of psychiatric disease (Rüsch et al. 2017). This finding raises the question of whether it is time to take a different approach. Taken these findings into consideration, our typology allows for a more tailored approach to psychotherapy and help. This approach could be a way to increase willingness to seek help and establish a relationship with the patient. Referring to the typology we introduced, it might be sensible to ask whether, for example, social and altruistic types such as the Comrade or the Corpsman are more likely to engage in therapy, regardless of psychotherapeutic school, if they are offered a group therapy setting at the outset or by offering a sports therapy programme to active types such as the Fighter, who quickly feel insecure in emotional contexts and use mechanisms, such as rationalization, trivialization, fighting, and powering out. Such a programme might be more inviting and would approach those former soldiers on their own terms before they are transferred to a more traditional therapeutic approach that focuses on communication and emotional insights, an approach with which those types might otherwise not be able to engage before their suffering has increased immensely. Individuals who may have internalized a very rigid male soldier ideal could, in this way, be slowly introduced to emotional topics. A subsequent psychodynamic or cognitive behavioural (psychotrauma) therapy, in accordance with proven guidelines and recommendations, would then be the second step. The same may be true of the Partisan, who would most likely benefit most from a mentalization-based therapy since it seems to be (psychoanalytically expressed) more a structural problem that prevents him from leading a balanced and successful life than a question of conflict.

We are fully aware of the fact that our attempt at type formation is only a first step that must be confirmed by further research. However, we believe it is necessary to develop new approaches to mental illness and the use of therapy for former GAF 
soldiers in order to counteract the suffering of individuals and their families. Due to the high number of unreported cases of mentally ill soldiers in need of treatment (Wittchen et al. 2012) and the growing number of traumatized individuals in recent times, we consider a new approach to be overdue.

We know that seeking help is not always a conscious, cognitive decision. In the decision process, many subconscious notions and stereotypical assumptions play a role and influence the outcome of this decision-making. Our typological classification creates initial insights into underlying motivations of conscious and unconscious coping and defense mechanisms and might be helpful in the adaptation of help on offer and therapy for the specific needs and abilities of various former soldiers. Additional research on conscious and unconscious coping mechanisms in traumarelated disorders is necessary independent of our results. From the point of view of care research, for example, the identification of individual core mechanisms, ideally at different examination times, could shed light on the influence of traumatic experiences on personal coping and defense styles and be used in the long term to create specific therapy regimes or for a more nuanced examination of the question of personal vulnerability.

The question also arises as to how far the types identified can also be found in other socio-cultural contexts. Are there such types in the American military, too? Would it not make sense to also consider an appropriate typology for the treatment of civilian patients with trauma-related disorders? After all, everyone has their own coping (and defense) mechanisms. Would it be an opportunity for all groups who find therapeutic access difficult to think about including coping and defense much more consciously in their therapy planning? This approach would mean that coping styles could be used to enable therapy by changing and reducing the individual's defenses.

\section{Critical Discussion of the Typological Construct}

Although critical opinions of typological constructs must be considered, it has to be stated that many of these concepts are well-known and are currently widely used, such as the Myers-Briggs-Test or the concept of Typus Melancholicus (Kronmüller et al. 2005). Many of the theoretical models and classification experiments by famous scientists such as Karl Jaspers and Kurt Schneider are based on typological constructs and have made their way into some parts of today's classification systems such as the DSM-IV (Jäger et al. 2016; Schäfer 2001).

The development of typologies has always been of great importance for better understanding and categorization of human behaviour, especially in the psychiatric context. According to Schäfer 2001, today the term 'type' is not a quantifiable scale that is used for the determination of individual characteristics. It instead represents a multi-dimensional prototype of patterns with which the individual can be compared. This comparison can be made via the endpoints of the continuum (extreme variants) or via gradual gradations on the continuum (accumulated types). In Anglo-American countries, the concept of type is given far less importance in personality research than in Central Europe. If the term 'type' is used at all, it is used in special cases. Especially in personality research, in the Anglo-American world, the term 'personality trait' is preferred to 'personality type'. As these 'traits' also occur with different degrees of 
expression and have no fixed boundaries, they are nonetheless very similar to the 'types' in many respects (Schäfer 2001).

Compared to categorical or dimensional approaches, typologies enable scientists and practitioners to use abstraction and reduction to make a complex process understandable and descriptive. In the past, critics of typological approaches rightly criticized the frequent lack of differentiation and validity of typological constructs. In relation to the past, this criticism is not completely unjustified. However, there are also counterexamples to the charge of lack of validity, such as the theory of personality functioning by Block and Block, who divided individuals into' resilient', over-controlled' and' undercontrolled' (Block and Block, 1980). The validity of the model was statistically confirmed in several studies (Bohane et al. 2017). Regardless, typological analysis is ideally carried out in three steps: 1) finding the types, 2) describing the types and 3) diagnosing the types using qualitative and quantitative methods (Zerssen 1973). We, therefore, see our attempt to identify defense and coping mechanism types in the group of former GAF soldiers as a first step in the generation of hypotheses (finding and describing the types), which will hopefully be followed by more qualitative and quantitative validation steps in the future.

\section{Strengths and Limitations}

The study is a pilot study for the identification, illustration and typological classification of conscious and unconscious coping mechanisms of former soldiers with deployment experience. With 43 interviews, the study has a broad database for a qualitative design. Due to the high media resonance and the additional recruitment in the hospital and within the military, we likely reached a very large number of former soldiers and included a large variability of contrasting cases through the differentiated sampling. Influences by the investigator and resulting psychodynamic processes were minimized by the sampling, the divergent team composition (medical doctors and psychological staff of both sexes with and without military and combat experience and with and without psychotherapeutic training in different psychotherapeutic schools), and analysed and included in the evaluation by the conscious handling of countertransference experiences and regular team intervention and supervision.

The open nature of the interview design with its low limitations, the lack of requirements and the possibility of asking questions led to very detailed, individual, subject-related descriptions of the internal and external processes. For most of the participants the interview situation, especially the conversation about stressful events in the war zone, was a challenge in itself. Therefore, some defense and coping mechanisms were already apparent during the interview which we were able to experience "live". Through the shown or not shown affect, the choice of words, the tone of voice and they kind of description, mechanisms were already recognizable in the interview situation. Our approach therefore involved, on the one hand, the analysis of the mechanisms remembered and narrated by the participants themselves, and, on the other hand, the consideration of the unconscious mechanisms and behaviours recognisable from the narrative. By the additional analysis of those mechanisms directly occurring in the course of the interview, we believe we counteracted a 
conscious or unconscious selection or distortion process, as occurs in any form of (retrospective) survey. In other words, these phenomena helped us to better understand the (unconscious) fears, values and motives of the former soldiers interviewed.

Although we have paid great attention to differentiated sampling with the aim of achieving the greatest possible heterogeneity and have always oriented our data collection and analysis to the quality criteria of Stamer et al. 2015, there is still no need for generalizability in the sense of statistical representativeness, as is generally not the case with any form of qualitative procedure. Our typological classification constitutes the preliminary results and theoretical model from a pilot study. It must and should be validated and critically reviewed, and evaluated for its practical usability, in followup studies.

\section{Conclusion}

This work strives for the first time, to our knowledge, to develop a typological classification of the use of conscious and unconscious defense and coping mechanisms on the basis of methodically and structurally collected and analysed data from a qualitative pilot survey of former soldiers in Germany. Seven coping and defense types were identified: the Fighter, the Comrade, the Corpsman, the Strategist, the Partisan, the Self-Protector and the Infantryman. The types identified differed in the accumulation, combination, and use of their conscious and unconscious defense and coping mechanisms in categories in the superordinate areas of behaviour, relationships, emotions, reflexivity and time focus. The typological classification could offer psychotherapeutic interventions tailored to individuals and their defense and coping mechanisms, which could lead to improved therapy use and compliance. Nevertheless, further research is needed in the field of trauma management and validation and verification of our results in follow-up studies.

Open Access This article is distributed under the terms of the Creative Commons Attribution 4.0 International License (http://creativecommons.org/licenses/by/4.0/), which permits unrestricted use, distribution, and reproduction in any medium, provided you give appropriate credit to the original author(s) and the source, provide a link to the Creative Commons license, and indicate if changes were made.

\section{References}

Beutel, M. (1990). Coping und Abwehr - Zur Vereinbarkeit zweier Konzepte [coping and defense - on the compatibility of two concepts]. In F. A. Muthny (Ed.), Krankheitsverarbeitung. Hintergrundtheorien, klinische Erfassung und empirische Ergebnisse [disease processing. Background theories, clinical coverage and empirical results.]. Heidelberg: Springer-Verlag.

Block, J., \& Block, J. (1980). The role of ego-control and ego-resiliency in the organisation of behaviour. In W. A. Collins (Ed.), Th Minnesota symposia on child psychology (pp. 39-101). Hilsdale: Lawrence Erlbaum Associates, Inc..

Bohane, L., Maguire, N., \& Richardson, T. (2017 Nov). Resilients, overcontrollers and undercontrollers: A systematic review of the utility of a personality typology method in understanding adult mental health problems. Clinical Psychology Review, 57, 75-92. https://doi.org/10.1016/j.cpr.2017.07.005.

Brants L., et al (2018). Abwehr und Coping ehemaliger Bundeswehrsoldaten in kritischen Lebensphasen [Defense and coping mechanisms of former Bundeswehr soldiers in critical life-phases]. Lecture on panel 
discussion: Der ehemalige Soldat in der deutschen Gesellschaft [The former soldier in German society] at the annual conference of the German-speaking Society for Psychotraumatology (DeGPT) in Dresden, Germany.

Carver, C. S., Scheier, M. F., \& Weintraub, J. K. (1989). Assessing coping strategies: A theoretically based approach. Journal of Personality and Social Psychology, 56(2), 267-283.

Chang, C.-M., Lee, L.-C., Connor, K. M., Davidson, J. R. T., Jeffries, K., \& Lai, T.-J. (2003). Posttraumatic distress and coping strategies among rescue workers after an earthquake. The Journal of Nervous and Mental Disease, 191, 391-398.

Chapman, A.L., Hadfield, M., Chapman, C.J. (2015). Qualitative research in healthcare: an introduction to grounded theory using thematic analysis. J R Coll Physicians Edinb, (45): 201-205.

Cierpka M (Hrsg.) (2014) Operationalisierte Psychodynamische Diagnostik OPD-2. Das Manual für Diagnostik und Therapieplanung. [Operationalized Psychodynamic Diagnostics OPD-2. The Manual for Diagnostics and Therapy Planning].Arbeitskreis zur Operationalisierung Psychodynamischer Diagnostik. 3., überarb. Aufl. Bern (Huber).

Cierpka, M., Rudolf, G., Grande, T., et al. (2007). Operationalised psychodynamic diagnostics (OPD). Clinical relevance, reliability and validity. Psychopathology, 40, 209-220.

Corbin, J. M., \& Strauss, A. L. (2008). Basics of qualitative research. Techniques and procedures for developing grounded theory (3rd ed.). Los Angeles: Sage Publ.

Dresing, T, Pehl, T, Schmieder, C. (2015): Manual (on) Transcription. Transcription Conventions, Software Guides and Practical Hints for Qualitative Researchers. 3rd English Edition.

Freud, A. (2006[1936]). Das Ich und die Abwehrmechanismen [Ego and the Mechanisms of Defense]. 19. Aufl. Frankfurt a. M. (Fischer Taschenbuchverlag).

Gigerenzer, G., \& Kober, H. (2009). Bauchentscheidungen. Die Intelligenz des Unbewussten und die Macht der Intuition [Gut Feelings: The Intelligence of the Unconscious]. 10. Aufl. München (Goldmann).

Guest, G., MacQueen, K.M., Namey, E.E. (2012). Introduction to applied thematic analysis. Applied Thematic Analysis. Thousand Oaks, CA Sage: 3-20.

Hentschel, U., Draguns, J. G., Ehlers, W., \& Smith, G. (2004). Defense mechanisms: Current approaches to research and measurement. In U. Hentschel, G. Smith, J. G. Draguns, \& W. Ehlers (Eds.), Advances in psychology, 136. Defense mechanisms: Theoretical, research and clinical perspectives (pp. 3-41). Oxford: Elsevier Science Ltd.

Hoge, C. W., Castro, C. A., Messer, S. C., McGurk, D., Cotting, D. I., \& Koffman, R. L. (2004). Combat duty in Iraq and Afghanistan, mental health problems, and barriers to care. The New England Journal of Medicine, 351(1), 13-22.

Horr, N. K., Braun, C., \& Volz, K. G. (2014). Feeling before knowing why: The role of the orbitofrontal cortex in intuitive judgments-an MEG study. Cognitive, Affective, \& Behavioral Neuroscience, 14(4), 12711285. https://doi.org/10.3758/s13415-014-0286-7.

Iversen, A. C., van Staden, L., Hughes, J. H., Browne, T., Greenberg, N., Hotopf, M., et al. (2010). Helpseeking and receipt of treatment among UK service personnel. The British Journal of Psychiatry: the Journal of Mental Science, 197(2), 149-155. https://doi.org/10.1192/bjp.bp.109.075762.

Jäger, M., Becker, T., \& Wigand, M. E. (2016). Das Typuskonzept in der Psychiatrie - Überlegungen nach Max Weber und Karl Jaspers. [The Concept of Typology in Psychiatry in the Context of Historical Contributions of Max Weber and Karl Jaspers]. Fortschritte der Neurologie-Psychiatrie, 84, 480-486.

Johnsen, B. H., Eid, J., Laberg, J. C., \& Thayer, J. F. (2002). The effect of sensitization and coping style on post-traumatic stress symptoms and quality of life. Two longitudinal studies. In: Scand J Psychol, 43(2), 181-188. https://doi.org/10.1111/1467-9450.00285.

Kato, T. (2015). Frequently Used Coping Scales: A Meta-Analysis. In: Stress and health. journal of the International Society for the Investigation of Stress 31 (4): 315-323. https://doi.org/10.1002/smi.2557.

König, K. (1997). Abwehrmechanismen [Defense Mechanisms]. Göttingen: Vandenhoeck \& Ruprecht.

König, K. (2004). Charakter, Persönlichkeit und Persönlichkeitsstörung [Character, personality and personality disorder.]. Stuttgart: Klett-Cotta.

Kowalski, J.T., Hauffa, R., Jacobs, H., Höllmer, H., Gerber, W.D., Zimmermann, P. (2012). Deploymentrelated stress disorder in german soldiers: utilization of psychiatric and psychotherapeutic treatment. Dtsch Arztebl Int, 109(35-36), 569-575.

Kronmüller, K. T., Backenstrass, M., Kocherscheidt, K., Hunt, A., Fiedler, P., \& Mundt, C. (2005). Dimensions of the typus melancholicus personality type. European Archives of Psychiatry and Clinical Neuroscience, 255, 341-349. https://doi.org/10.1007/s00406-005-0572-z.

Küsters, I. (2014). Narratives Interview [Narrative Interview]. In: Handbuch 1060 Methoden der empirischen Sozialforschung (pp. 575-580), Wiesbaden: Springer VS.

Laughlin, H. P. (1979). The ego and its defenses (2nd ed.). New York: Aronson. 
Lazarus, R.S., \& Launier, R. (1981). Stressbezogene Transaktionen zwischen Personen und Umwelt [Stressrelated transactions between person and environment]. In: Jürgen R. Nitsch und Henning Allmer (Hrsg). Stress. Theorien, Untersuchungen, Maßnahmen. Bern (Huber): 213-259.

Lazarus, R.S., \& Folkman, S. (1984). Stress, Appraisal and coping. Springer, New York.

Lazarus, R.S. (2000). Toward better research on stress and coping. American Psychologist, 55(6): 665-673. https://doi.org/10.1037//0003-066X.55.6.665.

Murphy, D., \& Busuttil, W. (2015). PTSD, stigma and barriers to help-seeking within the UK armed forces. Journal of the Royal Army Medical Corps, 161(4), 322-326. https://doi.org/10.1136/jramc-2014-000344.

Olff, M., Langeland, W., \& Gersons, B. P. R. (2005). The psychobiology of PTSD: Coping with trauma. Psychoneuroendocrinology, 30(10), 974-982. https://doi.org/10.1016/j.psyneuen.2005.04.009.

Rubino, I. A., Saya, A., \& Siracusano, A. (2007). Signs of defense in obsessive-compulsive disorder: A validation study of the defense mechanism test. Perceptual and Motor Skills, 105(3_suppl), 1139-1142.

Rudolf, G., Horn, H., \& Cierpka, M. (2004). Strukturbezogene Psychotherapie [Structure-oriented psychotherapy]. Stuttgart: Schattauer.

Rüsch, N., Rose, C., Holzhausen, F., Mulfinger, N., Krumm, S., Corrigan, P. W., Willmund, G. D., \& Zimmermann, P. (2017). Attitudes towards disclosing a mental illness among German soldiers and their comrades. Psychiatry Research. https://doi.org/10.1016/j.psychres.2017.08.028.

Sayer, N. A., Friedemann-Sanchez, G., Spoont, M., Murdoch, M., Parker, L. E., Chiros, C., \& Rosenheck, R. (2009). A qualitative study of determinants of PTSD treatment initiation in veterans. Psychiatry: Interpersonal and Biological Processes, 72(3), 238-255. https://doi.org/10.1521/psyc.2009.72.3.238.

Sayer, N. A., Spoont, M., \& Nelson, D. B. (2004). Disability compensation for PTSD and use of VA mental health care. Psychiatric services (Washington, D.C.), 55(5), 589. https://doi.org/10.1176/appi.ps.55.5.589.

Sayer, N. A., Clothier, B., Spoont, M., \& Nelson, D. B. (2007). Use of mental health treatment among veterans filing claims for posttraumatic stress disorder. Journal of Traumatic Stress, 20(1), 15-25. https://doi. org/10.1002/jts.20182.

Schäfer, M. L. (2001). (2001). The significance of the type concept in psychiatry. Fortschritte der NeurologiePsychiatrie, 69, 256-267.

Schuy, K., Brants, L., Dors, S., Horzetki, M., Willmund, G., Ströhle, A., ... Siegel, S. (2019). Psychological Stigma Costs as Barriers to Healthcare Use in Former Soldiers of the German Armed Forces: A Qualitative Analysis. Military psychology, Acepted: March 201, 10.1080/08995605.2019.1598228.

Schuy, K., Brants, L., Dors, S., Ströhle, A., Zimmermann, P. L., Willmund, G., et al. (2018). "Treffer im Kopf" - Stigma psychischer Erkrankungen als Einflussfaktor auf die Inanspruchnahme von Hilfsangeboten durch VeteranInnen der Bundeswehr [Mental Health Stigma: An Influencing Factor in Healthcare Utilization by Veterans of the German Armed Forces]. Das Gesundheitswesen, 80, 1-8.

Schwarzer, R. (1998). Stress and coping resources. Theory and review. In: Schwarzer, R. (Hrsg.). Advances in Health Psychology Research. CD ROM Volume. Berlin (Freie Universität).

Siegel, S., Rau, H., Dors, S., Brants, L., Börner, M., Mahnke, M., et al. (2017). Barrieren der Inanspruchnahme von Psychotherapie ehemaliger Soldatinnen und Soldaten der Bundeswehr (Veteranen). Eine Expertenbefragung. [Barriers to treatment-seeking among German veterans: expert interviews] Zeitschrift Für Evidenz. Fortbildung Und Qualität Im Gesundheitswesen, 125, 30-37.

Stamer, M., Güthlin, C., Holmberg, C., Karbach, U., Patzelt, C., \& Meyer, T. (2015). für die Arbeitsgruppe Qualitative Methoden des Deutschen Netzwerks Versorgungsforschung (DNVF) e.V.: Qualitative Studien in der Versorgungsforschung - Diskussionspapier, Teil 3: Qualität qualitativer Studien [Qualitative Methods of the German Network for Supply Research (DNVF): Qualitative Studies in Supply Research - Discussion Paper, Part 3: Quality of Qualitative Studies]. Gesundheitswesen, 77, 966-975.

Stecker, T., Fortney, J. C., Hamilton, F., Ajzen, I. (2007): An Assessment of Beliefs About Mental Health Care Among Veterans Who Served in Iraq. In: Psychiatric Services 58 (10), S. 1358-1361, zuletzt geprüft am 30.06.2016.

Steffens, W., \& Kächele, H. (1988). Abwehr und Bewältigung - Mechanismen und Strategien. Wie ist eine Integration möglich? [Defense and Coping - Mechanisms and Strategies. How is integration possible?] In: Steffens, W. \& Kächele, H. (Hrsg.). Bewältigung und Abwehr. Beiträge zur Psychologie und Psychotherapie schwerer körperlicher Krankheiten [Coping and Defense. Contributions to the Psychology and Psychotherapy of Severe Physical Illnesses]. Heidelberg, Springer: 1-50.

Teddlie, C., \& Yu, F. (2007). Mixed methods sampling. A typology with examples. In: Journal of Mixed Methods Research, 1(1), 77-100. https://doi.org/10.1177/2345678906292430.

Vaillant, G. E. (1971). The theoretical hierarchy of adaptive ego mechanisms. Archives of General Psychiatry, $24,107-118$.

Vaillant, G. E. (1992). The ego and mechanisms of defense. Washington DC: American Psychiatric Press. 
Wang, P. S., Lane, M., Olfson, M., Pincus, H. A., Wells, K. B., \& Kessler, R. C. (2005). Twelve-month use of mental health services in the United States: Results from the National Comorbidity Survey Replication. Archives of General Psychiatry, 62(6), 629-640. https://doi.org/10.1001/archpsyc.62.6.629.

Wöller, W. (2013). Trauma und Persönlichkeitsstörungen. Ressourcenbasierte Psychodynamische Therapie (RPT) traumabedingter Persönlichkeitsstörungen [Trauma and personality disorders. Resource-based Psychodynamic Therapy (RPT) of trauma-related personality disorders]. Stuttgart: Schattauer GmbH Verlag für Medizin und Naturwissenschaften.

Wittchen, H.-U., Schönfeld, S., Kirschbaum, C., Thurau, C., Trautmann, S., Steudte, S., et al. (2012). Traumatic experiences and posttraumatic stress disorder in soldiers following deployment abroad: How big is the hidden problem? Deutsches Ärzteblatt International, 109(35-36), 559-569.

v Zerssen, D. (1973). Methoden der Konstitutions- und Typenforschung. In: Enzyklopädie der Geisteswissenschaften [Methods of constitutional and typology research. In: Encyclopedia of the Humanities]. Thiel M (Hrsg). Methoden der Anthropologie, Anthropogeographie, Völkerkunde und Religionswissenschaft. München, Wien, Oldenburg: 35-143.

Publisher's Note Springer Nature remains neutral with regard to jurisdictional claims in published maps and institutional affiliations. 